\title{
Strategic Quality Control Measures to Reduce Defects in Composite Wind Turbine Blades
}

\author{
U.I.K. Galappaththi1, A.M. De Silva ${ }^{2}$, Milos Draskovic ${ }^{3}$ M Macdonald $^{4}$, \\ School of Engineering and Built Environment, Glasgow Caledonian University, Glasgow, UK ${ }^{124}$ \\ Institute of Aircraft Design, University of Stuttgart, Germany ${ }^{3}$ \\ Udayanga.galappaththi@gcu.ac.uk ${ }^{1}$, A.Desilva@gcu.ac.uk ${ }^{1}$, draskovic@ifb.uni-stuttgart.de ${ }^{3}$, M.Macdonal@gcu.ac.uk
}

\begin{abstract}
.
Wind turbine blades are made from polymer composites to provide high specific stiffness, strength, and good fatigue performance. However, large composite structures are prone to manufacturing defects such as delamination and adhesive failure, which can lead to crack initiation and propagation under cyclic stresses. National renewable energy laboratory, USA statistics shows $26 \%$ fatigue failure modes are created by laminate and adhesive joint manufacturing errors. A range of manufacturing processes are used to construct wind turbine blades. Resin transfer infusion is one of the most frequently used methods in wind turbine blade manufacturing industry. This paper provides assessment on regular defects occurring in resin transfer infusion processes which lead to poor quality in wind turbine blade manufacture. The assessment is based on the existing literature and the know-how generated from manufacturing wind turbine blades. The effect of these defects for the structural failure of composite wind turbine blades is analysed. The final phase of the study provides manufacturing quality control measures which can be implemented to improve the composite wind turbine blade manufacturing process.
\end{abstract}

\section{Key words}

Wind turbine blade, resin infusion, composites, manufacturing defects, and quality control

\section{Introduction}

Several dramatic failures of utility-scale wind turbine rotor blades have emerged in the industry news during the past few years. Manufacturing defects and in-service damages are the main reasons for early blade failures.

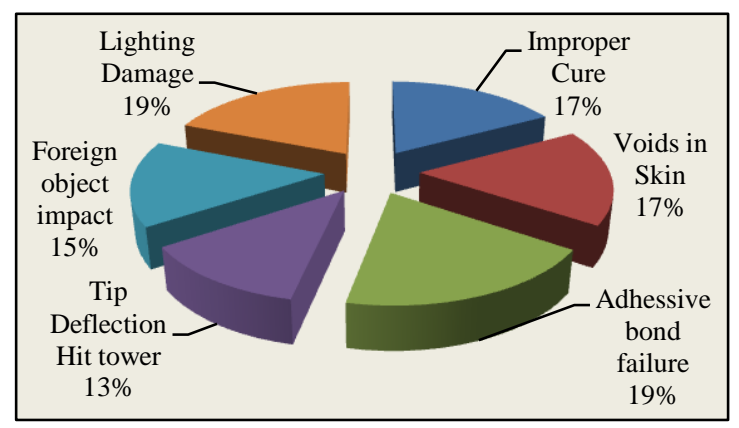

Fig.1. Blade damages at manufacturing and operational stages [1]
Adhesive bond failure, voids in the skin and improper cure are the key manufacturing defects which cause wind turbine blade failure [1].According to the National Renewable energy laboratory (NREL), $33 \%$ of the fatigue failure is caused by laminate design and manufacturing errors [1].

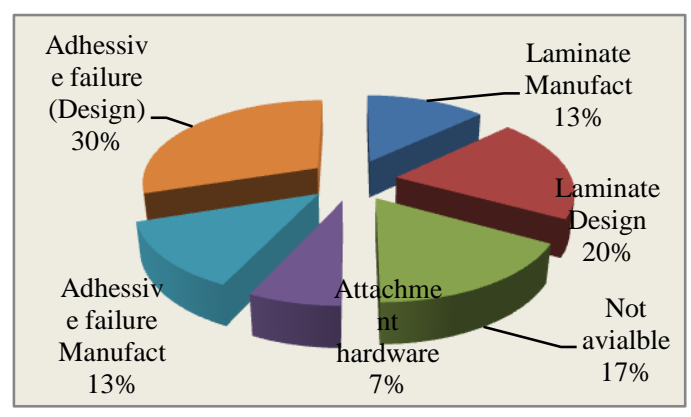

Fig. 1. Composite wind turbine blade failure modes [1]

Renewable-UK has confirmed that (Daily telegraph-1 $1^{\text {th }}$ December-2011) 1500 accidents have occurred in the UK from the Period of 2006-2011. Further, most of the incidents were due to blade failures [2]. These accidents create casualties, property damages and major financial losses. There were several other incidents which made major financial losses. Suzlon Energy Ltd, the world's fifth leading wind turbine manufacturer, announced a retrofit program to resolve blade cracking issues that have been discovered during the operations of some of its "S88" turbines in February 2010. The estimated cost of the retrofit program was $\$ 25$ million [3].

In this context, classification of manufacturing defects, identification of their influence on failure of wind turbine blades and implementation of quality control measures to reduce the defects in wind turbine blades is a significant task. Various manufacturing process are used to manufacture wind turbine blades, which include wet layup, pre-preg, resin infusion, compression moulding, pultrusion, wood-epoxy saturation technique and filament winding [4]. The main objective of this paper is to discuss the key manufacturing defects arising from the resin transfer infusion process and their influence on the structural failure of composite wind turbine blades. The quality control measures are introduced to reduce the defects in wind turbine blade manufacture. 


\section{Methodology}

The first stage of the project was a comprehensive literature review to study and identify the type of manufacturing defects induces from resin transfer infusion process base composite wind turbine blade production. The analysis also extended to identify the effect of these defects for the failure of composite wind turbine blades.

The second stage of the project was focused to classify sources of defects and manufacturing process parameters which should necessary to be controlled to avoid identified defects.

As the third stage of the project four small wind turbine blades were manufactured from resin transfer infusion process.

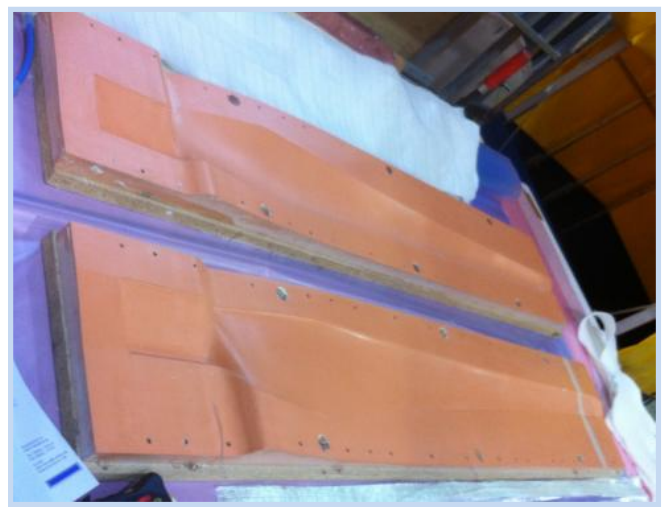

Fig. 3. The moulds use for wind turbine blade manufacture

Identified manufacturing process parameters were change to embed manufacturing defects in turbine blade structures.

The final stage of the project was implementation of manufacturing quality control measures to reduce defects in wind turbine blades.

\section{Manufacturing Defects}

Imperfections of resin transfer infusion base wind turbine blade manufacturing process can be summarised as follows.

- Voids and dry spots

- Ply waviness

- Variation in the thickness and fibre volume

- Delaminations

- Adhesive bonding Failure

\section{A. Voids and dry spots}

Voids

Voids are the result of leaks in the moulds, fabric architecture, dissolved gas in the resin, boiling of styrene or other volatile resin components, or mechanical entrapment due to mixing [5], [6], [7].

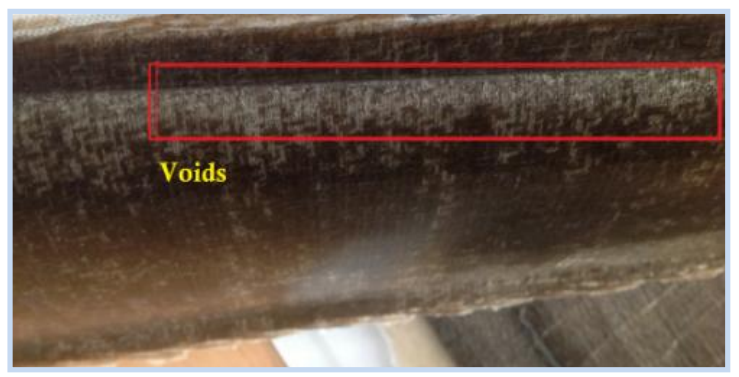

Fig.4. Voids

Leaks in the moulds should be avoided to prevent voids. Sharp geometrical edges in the turbine moulds, pleats in the secondary mould seal can create leaks. Further, if the mould cavity is manufactured from wood, the porosity of mould material can create leaks.

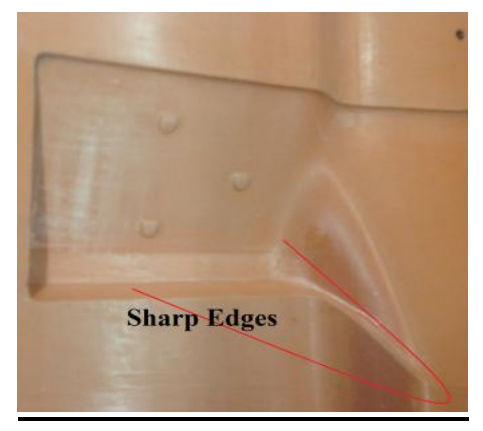

Fig.5. Sharp Edges of the blade mould

One of the critical sources of void formation in the infusion process is related to fabric architecture [8]. Fabric architecture refers to the method of combining the tows to form a fabric. Reinforcement fabrics with a -nonuniform microstructure have two levels of permeability, the inter-tow region and the intra-tow region (Permeability: A geometric parameter of the fabric which quantifies how easily fluid will flow through). These two levels of permeability lead to two level of microscopic infusion and result in voids. The studies show that void content and injection velocity also correlated, with each fabric having its optimal velocity resulting in minimum voids [8].

\section{The effect of voids for mechanical properties}

The amount of void content extensively affects mechanical properties and every $1 \%$ increase in interlaminar voids reduces $7 \%$ of mechanical properties (shear strength, flexural strength, longitudinal and transverse strength, compressive strength and fatigue performance) [9].

\section{Dry spots}

Dry spot is an area of the laminate which is not permeated by the resin. In proper mould design (Point $B$ : Sharp and curved Edges) and poor infusion layout (i.e., race tracking or bottlenecking: Point A: Race tracking) are the key reasons for dry spots [10] 


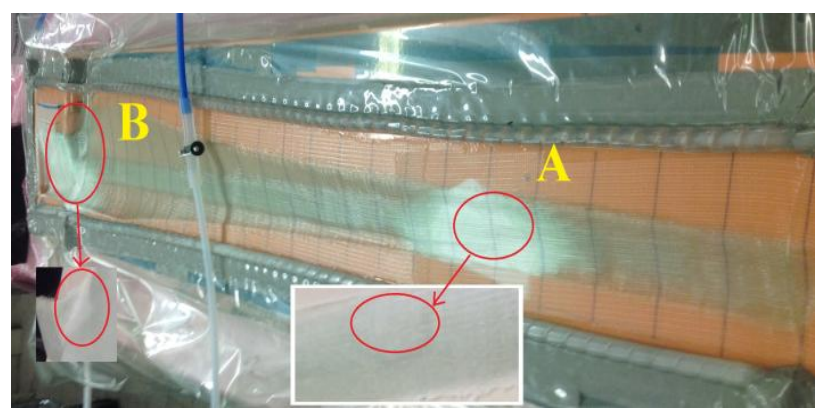

Fig.6. Dry Spots

\section{The effect of dry spots for mechanical properties}

Dry spots eliminate the interaction of fibres and resin, thus significantly reduce the mechanical properties.

\section{B. Fibre Ply waviness}

Wind turbine blades are manufactured from large tow fabrics to build up thickness rapidly, but these are more likely to lead to defects such as waviness, dry patches, etc. Such defects will lead to local delamination or ply failure.

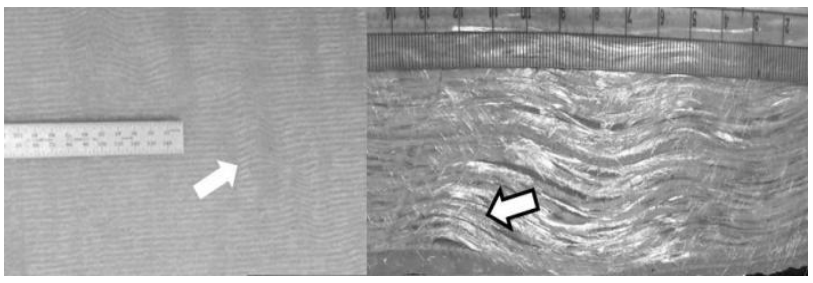

Fig.7. In-Plane waves seen on the surface (left); Out-of-Plane (OP) waves right seen in a cross-section of a turbine blade (right) [11]

Ply waviness is caused by different factors, some of them include: geometric changes on tooling surfaces, operator errors in layup and skewed fibres.

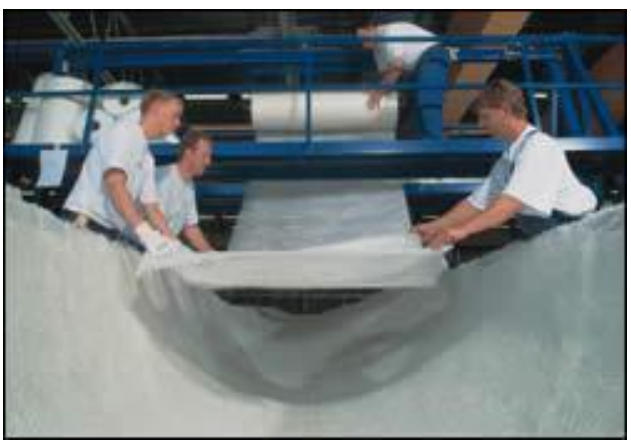

Fig.8. Laying Up of Glass Mat for Vacuum Resin Infusion (Source: ptonline.com)

\section{The effect of ply waviness on mechanical properties}

Fibre waviness affects the compressive, tensile, and flexural strength of composites. The in plane waviness increases the modulus of elasticity [11].Further compressive and tensile strength are reduced to $25 \%$ to $54 \%$ of the control for waves. For wavy specimens delamination is the main cause for failure and involves progressive matrix cracking, ply delamination, load redistribution and ultimately ply failure. Fibre waves reduce the ultimate failure stress of wavy specimens to about $74 \%-77$ of $\mathrm{S}_{\max }$ (where $\mathrm{S}_{\max }$ is the reference ultimate failure stress of flat laminates). Further, fibre waviness creates delamination of structures under even lower stress levels (32\%-38\% of Smax) and significantly reduces fatigue properties of composites [12].

\section{Variation in thickness and fibre volume}

Variation in thickness and fibre volume is another problematic issue observed in manufacturing process. The thickness variation results from vacuum pressure gradient and is inversely proportional to the pressure gradient [13].

Spring-back at different pressures [14], the height variation in tooling surfaces [15] and infusion layout can cause thickness variations.

The following figure illustrates the layout used for produce section of a turbine blade. The infused blade section has showed $12 \%-20 \%$ of thickness variation across the length of the blade. This is because of the higher pressure gradient and tooling height variation. The higher pressure can be avoided by reducing the inletoutlet pressure gradient by changing infusion layout. The effect of tooling surface can be reduced by applying "stage infusion"

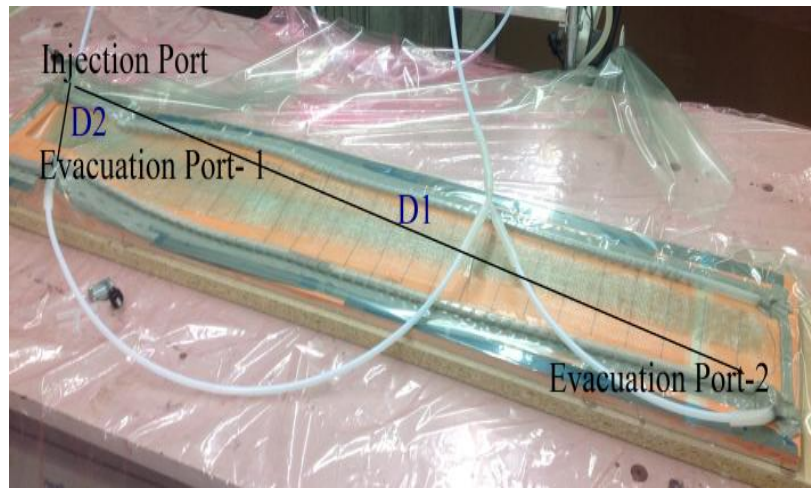

Fig. 9. Infusion layout

The effect of dry spots for mechanical properties

The fibre volume fraction is inversely proportional to laminate thickness' [16]. All mechanical properties depend on fibre volume fraction. Therefore thickness variation directly affects the mechanical properties.

\section{Delaminations}

Delaminations are areas of poor or no bonding between adjacent plies which can be caused by air traps, a poor infusion of resin in the given area or similar, dependent of the production process and geometry discontinuities. The following figure shows the delamination created by poor infusion (which has resulted in dry spots). 


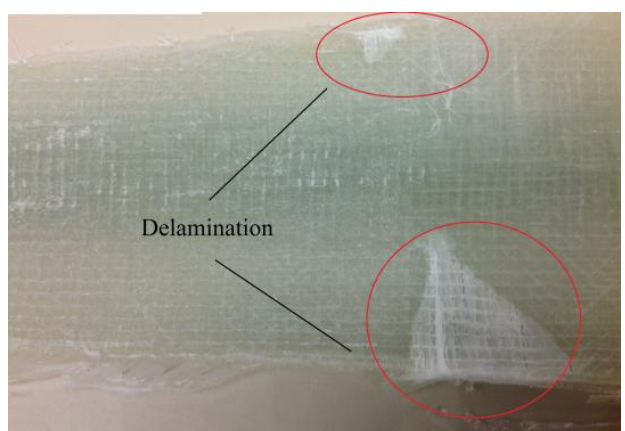

Fig.10. Delamination

The effect of delamination on mechanical properties

Compressive strength of wind turbine blade is reduced by delamination because of out-of-plane buckling [17]. In fatigue loading, delamination creates high stress concentration areas which will further increase crack growth and significantly reduce the fatigue life of wind turbine blades.

The mode of buckling is determined by the position of the delamination. If it is placed near the outer or inner surface of the laminate the delamination induces local buckling of a group of plies. If the delamination is placed near the centre of the material the strength reduction will be caused by global buckling of the laminate [18].

Large delamination creates high probability of failure in ultimate loading. However large delamination can be detected by available non-destructive quality control methods. Smaller delaminations are much harder to detect and can grow due to stress concentrations. This can have a significant influence on the fatigue and ultimate capacity later in the service life [19].

\section{E. Adhesive Bonding Failure}

Adhesive bonding failure is another key manufacturing defectTypical blade joints use paste adhesives several millimetres thick, of varying geometry. They can be expected to experience significant static and fatigue loads under various environmental conditions over their service life. The limited data available for joints of this class with metal or composite adherents indicate significant sensitivity to adhered properties and surface preparation, adhesive composition (chemistry, additives, mixing, curing), adhesive thickness, temperature, and moisture, as well as joint geometry [20] There were different research studies to investigate the effect of adhesive bonding for fatigue failure of wind turbine blades. However, the effect of secondary bonding is primarily applicable for large scale wind turbine blades failure.

\section{Process Parameters of Resin Infusion Process}

The manufacturing defects of resin infusion process can be reduced by controlling resin process parameters efficiently. The key parameters of resin infusion process include:
a) Cross section of the Laminate
b) Permeability
c) Pressure difference
d) Resin viscosity
e) Infusion velocity
f) Resin viscosity

This behaviour was first observed and described by the French engineer Henry Darcy in 1856, and is predicted by Darcy's Law given in Equation 2.10 [21].

$$
v=\frac{\eta}{A}=\frac{K * \Delta P}{\mu * \Delta x}
$$

Understanding and controlling these variables will lead to predictable and repeatable resin flow progression during resin infusion. Failing to understand and control these variables leads to incomplete infusions and dry spots which can be costly and sometimes difficult to repair.

\section{Strategic Quality Control Measures to Reduce Defects}

The influence of manufacturing defects on the failure of wind turbine blades can be reduced by implementing best quality control practices. The variations of production process parameters highly affect the quality of the blades, therefore, a best quality control system for wind turbine production should link quality assurance and production process control. Fig.11. illustrate the proposed strategic system.

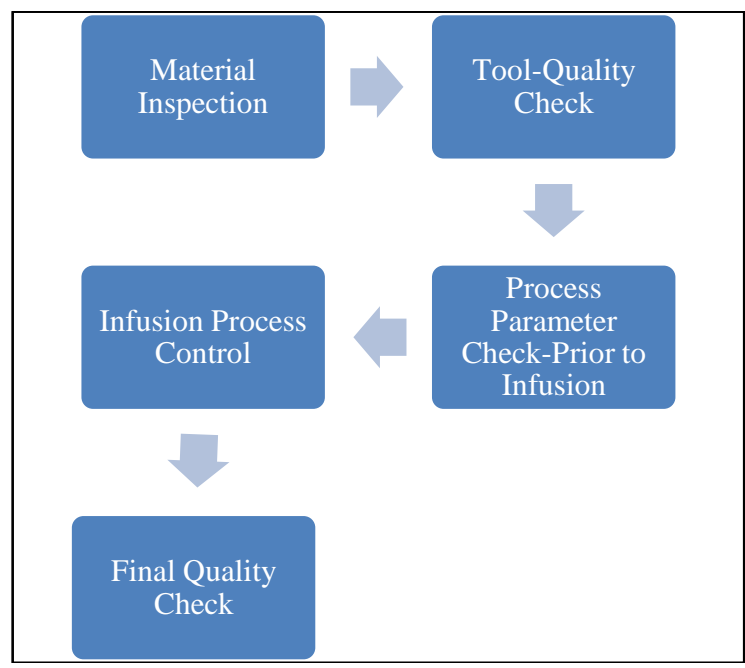

Fig.11.Proposed Strategic Quality Control System 


\section{A. Material Inspection (Incoming and after storage)}

Incoming material inspection is the first stage of quality assurance process. The materials (Fibre, resin and other chemicals) should not me contaminated, damaged or expired. Further, it is important to check dimensions, service temperatures, pressures, electrical requirements, physical requirements, service life, and load regulations, environmental influences are matching with design requests or material specification [22].

The material inspection process should be continued at the two stages: (1) Incoming material to be stored (from supplier), (2) Material fed into production (From the storage). Therefore it is also important to maintain effective storage requirement of material as well.

\section{B. Quality inspection of Tooling}

Proper condition of tooling is necessary to avoid shortcomings. Therefore it is necessary to inspect quality of blade moulds and access the working condition of all machinery before starting the production process.

\section{Preliminary checking prior to infusion (Pressure and Weight)}

The infiltration process is highly depending on the preliminary setup and it is essential to carry out required quality checking and recording before starting infiltration.

- Mould Cleaning (Quality Check)

- Mixing of Resin (Quantity check, recorded and proper mixing)

- Bubble Nucleation (Pressure check and visual inspection)

- Leak check

- Pressure Drop Test

- Fibre layup Humidity and temperature)

- Manufacturing Environment control

\section{Infusion-Process control}

The infusion velocity and pressure variation across the mould cavity are essential process parameters, which should be properly controlled in the infusion process. Pressure gauges and flow meters should be used to measure pressure and flow rate (Infused velocity).

\section{E. Quality controlling of turbine blades}

Non Destructive Inspection (NDI) such as visual inspection or ultrasound scanning is performed after production in order to identify manufacturing defects from the of wind turbine blades.

In the context of small scale wind turbine blade production, it is important to identify most suitable and low cost NDT technique to identify defects in turbine blades. The Appendix I presents summary of NDT techniques that can be used for wind turbine blade inpection[23]

\section{Conclusion}

Manufacturing quality is a critical issue for improved reliability of wind turbine blades. Voids, dry spots, ply waviness, thickness variation, delamination and adhesive bonding failure are the key defects in resin infusion based wind turbine blade production. Each of these defects affects the structural properties (ultimate failure strength, stiffness, flexural strength, etc). Wind turbine manufactures use higher safety factors to reduce the influence of these defects and this increases cost of turbine blade manufacturing. Consequently it is significant to reduce these defects to improve reliability of turbine blades. In this context, identification of manufacturing defects, their influence on structural liability and implementation of accurate production control and quality control measures is a critical task. The proposed approach is consists of five stages (1) Material Inspection, (2) Quality inspection of Tooling, (3) Infusion-Process control, (4) Preliminary checking prior to infusion and (5) Quality controlling of turbine blades.

\section{References}

[1] NENUPHAR, Wind farms designed for the offshore environment, June 2010, ABM Centre, 128 rue du Faubourg de Douai, 59000 LILLE - FRANCE

[2] Caithness Wind farm Information Forum, Summary of Wind Turbine Accident data to 30 Sept 2012, Available at: http://www.caithnesswindfarms.co.uk/page4.htm, [Accessed: 10th November 2012].

[3] Douglas S. Cairns, Trey Riddle, Jared Nelson, 2011, Wind turbine composite blade manufacturing: The need for understanding defect origins, prevalence, implications and reliability, Sandia National Laboratories , Albuquerque, California

[4] J F Manwell, J G Macgowan,A L Rogers, Wind energy explained, theory ,design and applications, ,2009 , ISBN 978-0-470-01500-1

[5] Afendi, M., Banks, W.M., \& Kirkwood, D. (2005). Bubble free resin for infusion process. Composites Part A: Applied Science and Manufacturing, 36(6). 739-746

[6] Lee, D.H., Lee, W.I., \& Kang, M.K. (2006). Analysis and minimization of void formation during resin transfer molding process. Composites Science and Technology, 66(16), 3281-3289.

[7] Kuentzer, N., Simacek, P., Advani, S.G., \& Walsh, S. (2007). Correlation of void distribution to VARTM manufacturing techniques. Composites Part A (Applied Science and Manufacturing), 38(3), 802-813.

[8] Leclerc, J.S., \& Ruiz, E. (2008). Porosity reduction using optimized flow velocity in Resin Transfer Molding. Composites Part A: Applied Science and Manufacturing, 39(12), 1859-1868.

[9] Judd, N.C.W., \& Wright, W.W. (1978). Voids and their effects on the mechanical properties of composites: an appraisal. SAMPE Journal, 14(1), 10-14.

[10] Bickerton, S., Sozer, E.M., Graham, P.J., Advani, S.G. (2000). Fabric structure and mold curvature effects on 
preform permeability and mold filling in the RTM process. Part I. Experiments. Composites - Part A: Applied Science and Manufacturing, 31(5), 423-438.

[11] Jared W. Nelson1, Douglas S. Cairns2, and Trey W. Riddle3, Manufacturing Defects Common to Composite Wind Turbine Blades: Effects of Defects, Montana State University, Bozeman, MT, 59717 Available at http://www.coe.montana.edu/composites/documents/2011 AIAA_2011_1756\%20Nelson.pdf

[12] U.I.K. Galappaththi, Anthony Picket, Milos Draskovic, Mark Capellaro, A.M. De Silva. The Effect of Ply Waviness for the Fatigue Life of Composite Wind Turbine Blades, Renewable Energy \& Power Quality Journal ( ISSN 2172038 X, No.11, March 2013)

[13] Tackitt, K.D., \& Walsh, S.M. (2005). Experimental study of thickness gradient formation in the vartm process. Materials and Manufacturing Processes, 20(4), 607-627.

[14] Yenilmez, B., \& Sozer, E.M. (2009). Compaction of e-glass fabric preforms in the Vacuum Infusion Process, A: Characterization experiments. Composites Part A: Applied Science and Manufacturing, 40(4), 499-510.

[15] Juska, T.D., Dexter, H.B., \& Seemann III, W.H. (1998). Pushing the limits of VARTM. International SAMPE Symposium and Exhibition (43rd: 1998: Anaheim, California), 43(1), 33-43.

[16] ASTM D 3171-06. (2006). Standard Test Methods for Constituent Content of Composite Materials. West Conshohocken, PA: ASTM International
[17] Hayman B, Wedel-Heinen J, Brondsted P. Materials challenges in present and future wind energy. Mrs Bulletin 2008 Apr;33(4):343-53

[18] Short GJ, Guild FJ, Pavier MJ. Themeffect of delamination geometry on themcompressive failure of composite laminates. Composites Science and Technology 2001;61(14):2075-86.

[19] Henrik Stensgaard Toft, Kim Branner, John Dalsgaard Sørensen 2007, Distribution of Defects in Wind Turbine Blades and Reliability Assessment of Blades Containing Defects

[20] Daniel D. Samborsky, 2009,Prediction of Delamination in wind turbine blades

[21] Hoebergen, A. (2001). Vacuum Infusion. In: ASM Handbook Vol. 21 Composites. ASM International.

[22] Bishop, G. (1991). Quality Assurance for Composites. Kunststoffe - German Plastics, 81(6), 18-21.

[23] U.I.K. Galappaththi, A.M. De Silva, M Macdonald, O Adewale, Review of Inspection and Quality Control Technologies for Composite Wind Turbine Blades, Insight Journal, Volume 54, February 2012,Doi:10.1784/insi.2012.54.2.82

\section{Appendix 1}

\begin{tabular}{|c|c|c|c|c|c|}
\hline & Visual Inspection & AcousticEmission & $\begin{array}{l}\text { Ultrason } \\
\text { ic testing }\end{array}$ & $\mathrm{X}$-ray inspection \\
\hline \multirow{2}{*}{$\begin{array}{l}\text { Applicable } \\
\text { Component } \\
\text { Geometries }\end{array}$} & Linear & $\mathrm{Y}$ & $\mathrm{Y}$ & $\mathrm{Y}$ & Y \\
\hline & Non-Linear & $\mathrm{Y}$ & $\mathrm{Y}$ & $\mathrm{Y}$ & $\mathrm{Y}$ \\
\hline \multirow[b]{3}{*}{$\begin{array}{l}\text { Detection } \\
\text { Capability }\end{array}$} & Surface & $\mathrm{Y}$ & $\mathrm{Y}$ & $\mathrm{Y}$ & $\mathrm{Y}$ \\
\hline & Sub-Surface & $\# 1$ & $\mathrm{Y}$ & $\mathrm{Y}$ & $\mathrm{Y}$ \\
\hline & Internal & $\# 1$ & $\mathrm{Y}$ & $\mathrm{Y}$ & $\mathrm{Y}$ \\
\hline \multicolumn{2}{|c|}{ Dynamic Detection } & $\mathrm{N}$ & $\mathrm{Y}$ & $\mathrm{N}$ & $\mathrm{N}$ \\
\hline \multirow{2}{*}{$\begin{array}{l}\text { Defect } \\
\text { Sizing }\end{array}$} & Length & $\mathrm{Y}$ & $\mathrm{Y}$ & $\mathrm{Y}$ & $\mathrm{Y}$ \\
\hline & Orientation & $\# 1$ & $*$ & $\mathrm{Y}$ & $\mathrm{Y}$ \\
\hline \multicolumn{2}{|c|}{ Defect Characterization } & $\mathrm{Y}$ & $\# 2$ & $\mathrm{Y}$ & $\mathrm{Y}$ \\
\hline \multicolumn{2}{|c|}{ Numerical Modeling } & $\mathrm{N}$ & $\mathrm{N}$ & $\mathrm{Y}$ & $\mathrm{Y}$ \\
\hline \multirow{7}{*}{$\begin{array}{l}\text { Types of } \\
\text { Damages } \\
\text { (micro } \\
\text { scale) }\end{array}$} & Fiber breakage & \#1 & $\mathrm{Y}$ & \#3 & \#4 \\
\hline & Fiber/matrix slip & $\# 1$ & $\mathrm{Y}$ & $*$ & \#4 \\
\hline & Matrix Cracks & $\mathrm{N}$ & $\mathrm{Y}$ & * & $\# 4$ \\
\hline & $\begin{array}{l}\text { Crack in } \\
\text { adhesions }\end{array}$ & $\mathrm{N}$ & $\mathrm{Y}$ & \#3 & $\# 4$ \\
\hline & Delamination & $\mathrm{N}$ & $\mathrm{Y}$ & $\# 3$ & $\# 4$ \\
\hline & $\begin{array}{l}\text { Laminate damage } \\
\text { involving fiber } \\
\text { fracture }\end{array}$ & $\mathrm{N}$ & $\mathrm{Y}$ & \#3 & \#4 \\
\hline & $\begin{array}{l}\text { Dynamic response } \\
\text { of structure }\end{array}$ & 1 & $\mathrm{~N}$ & \#3 & $\# 4$ \\
\hline
\end{tabular}

\begin{tabular}{|lll|}
\hline 1 & - & Allows to access by using visual technologies \\
$\mathrm{Y}$ & - & Possible \\
$\mathrm{N}$ & - & Not Possible \\
$*$ & - & Flexibility Exists \\
2 & - & Only Harmful \\
3 & - & Limited access (parallel surfaces and multilayered structures) \\
4 & - & Not possible for defects oriented parallel to rays (Otherwise YES) \\
\hline
\end{tabular}

